\title{
Click evoked otoacoustic emissions compared with brain stem electric response
}

\author{
J C STEVENS, ${ }^{*}$ H D WEBB, ${ }^{*} \mathrm{~J}$ HUTCHINSON, $\dagger \mathrm{J}$ CONNELL, $\dagger$ M F SMITH, $\ddagger$ AND \\ J T BUFFIN§
}

Departments of *Medical Physics and Clinical Engineering and §Ear, Nose and Throat, Royal Hallamshire Hospital; †Department of Audiology, Sheffield Children’s Hospital, and $¥$ North Trent Neonatal Intensive Care Unit, Jessop Hospital for Women, Sheffield

SUMMARY The hearing of 346 babies taken largely from a neonatal intensive care unit has been tested by otoacoustic emissions and brain stem electric response audiometry. A total of 336 $(97 \%)$ of the babies have been followed up by hearing tests from the age of 8 months. The otocoustic emission test has been found to be practical with a mean test time of $12 \cdot 1$ minutes compared with 21.0 minutes for brain stem electric response. An otoacoustic emission was recorded bilaterally in $274(79 \%)$ babies. Twenty of the 21 surviving infants who failed brain stem electric response in the neonatal period did not produce an emission. It is concluded that the otoacoustic emission test would make a good first screen to be followed by the brain stem electric response if no otoacoustic emission was present. There is poor agreement between the test results in the neonatal period and those of the follow up period, however, indicating the need for continuous monitoring of those babies failed by brain stem electric response.

Infants are not normally screened for hearing impairment before the age of 8 months when the ability to localise sounds is used. It is now generally agreed that the detection of hearing impairment before this age is desirable. Reports in the literature on the success of this screen at 8 months to detect a high proportion of the severely hearing impaired vary-for example, Newton reports a success rate of only $55 \%,{ }^{1}$ whereas McCormick indicates that a high success rate can be achieved with good organisation and training. ${ }^{2}$ The advent of equipment that measures such reflexes as movement, startle, and respiration and the use of the brain stem electric response has led to many studies of hearing at birth with varying degrees of success. For example Murray et al, in their review of the use of the brain stem electric response test, report a confirmation rate of 4.8 to $100 \%$ of hearing impaired from follow up studies of infants who failed the brain stem electric response test at birth. ${ }^{3}$

Recently another possible method of detecting hearing impairment at birth has arisen, that of click evoked otoacoustic emissions. The phenomenon was first reported by Kemp in $1978 . .^{4}$ Since then there have been many studies showing that the click evoked otoacoustic emission can be recorded in most normally hearing adults and more recently in normal newborns and in babies admitted to a special care unit. ${ }^{5-7}$ It has also been shown that the click evoked emission is not present in adults when the hearing loss exceeds about $15 \mathrm{~dB} .{ }^{4-10}$ The question remains as to whether it is possible to use the otoacoustic emission to identify the hearing impaired newborn infant. Since May 1985 we have been carrying out a prospective study to investigate this. As in other studies we have selected babies admitted to a neonatal intensive care unit as being a convenient test group where the incidence of hearing impairment is known to be higher than in the whole population.

One problem of prospective studies is that there is evidence that some hearing impairments detected by tests at birth appear to improve with age, ${ }^{3}$ and others may appear later on in the first year of life. ${ }^{11}$ To enable the results of the otoacoustic emission test to be compared with a second test at birth, brain stem electric response was carried out at the same time.

In an earlier paper we published results of tests on 30 normal newborns and preliminary results on the 


\section{Stevens, Webb, Hutchinson, Connell, Smith, and Buffin}

first 112 infants in the prospective study. ${ }^{7}$ This paper presents the results on the first 346 babies who have entered the study and who have been followed up to at least 12 months of age.

\section{Subjects and methods}

The aim of the prospective study was to test all babies admitted to the North Trent Neonatal Intensive Care Unit at the Jessop Hospital for Women in Sheffield. In practice only a proportion of the babies could be tested. In addition a small number of babies considered to be at risk of hearing impairment were tested as outpatients. During the period of testing reported here (August 1985September 1987) $43.3 \%$ of babies admitted were tested as inpatients before leaving the unit and a further $8.7 \%$ on recall as outpatients giving a total of $52 \%$. Excluding the $9.5 \%$ who died and the $1.6 \%$ who were in the unit for non-medical reasons there were several reasons for not testing the remaining $36.9 \%$. A total of $15.8 \%$ were only in for 48 hours and were not tested as the risk of hearing impairment was considered to be no different to normal newborns, $11.3 \%$ were missed but considered by the paediatrician to be at low risk and so not recalled, and $9.8 \%$ who had been transferred back to their referring unit could not be recalled.

The mean birth weight was $2220 \mathrm{~g}$ (range 540-4890) and the mean gestational age 34 weeks (range 24-42). The mean postconceptional age when tested was 37.5 weeks (range 32-49) for inpatients and 47 weeks (range 40-59) for outpatients.

Both ears of each baby were tested by otoacoustic emission and brain stem electric response. The tests were carried out as near as possible to the time at which the baby left the unit. If the baby was transferred to the referring unit when too young or too sick to test it was recalled, if possible, to be tested as an outpatient. Any baby that failed to produce a brain stem electric response at or below $43 \mathrm{~dB}$ normal hearing level ( $\mathrm{nHL}$ ) in one ear and $53 \mathrm{dBnHL}$ in the other was recalled for a further brain stem electric response test. Initially the criteria was $43 \mathrm{dBnHL}$ in either ear but this produced too many requiring a retest. It was argued that the modified criteria was acceptable as the management of the child would be unaffected by this change. Where possible a retest was carried out while the baby was still in the unit, otherwise it was carried out on an outpatient basis at 4-6 weeks corrected age (that is, post due date). Tympanometry was attempted as a means of investigating middle ear disease, but was abandoned as being too difficult to carry out on all babies. The methods for otoacoustic emission and brain stem electric response recording have been given in an earlier paper. ${ }^{7}$ The only modification since then was on the scoring of the recorded waveforms. The decision on the presence of a response was first made by the tester and an experienced user scoring independently. Where there was a disagreement then a third experienced user of these tests, scoring independently, was used to arbitrate.

All babies entering the study were recalled for distraction testing and tympanometry at 8 months corrected age. To pass the distraction test the baby had to elicit a full head turn to a range of stimuli covering the audiometric frequencies. It was intended that the persons involved in this follow up should have no knowledge of the results at birth. Although this was the case for most babies, in a few instances, particularly where the tests at birth had involved considerable follow up, it was possible that the tester could gain some knowledge of the results at birth. All babies not passing the distraction test at $30 \mathrm{dBnHL}$ in each ear were recalled at approximately three to six month intervals until they were passed at this level.

Table 1 Neonatal screen and follow up tests to 3 months corrected age

\begin{tabular}{|c|c|c|c|}
\hline & $\begin{array}{l}\text { First } \\
\text { screen }^{*} \\
(n=346)\end{array}$ & $\begin{array}{l}\text { Second } \\
\text { test } \\
(n=42)\end{array}$ & $\begin{array}{l}\text { Final } \\
\text { outcome } \\
(n=346)\end{array}$ \\
\hline \multicolumn{4}{|l|}{$\begin{array}{l}\text { No }(\%) \text { with no } \\
\text { otoacoustic emiss }\end{array}$} \\
\hline \multicolumn{4}{|l|}{ No $(\%)$ who passed } \\
\hline BSER & & $18(5 \cdot 2)$ & $323(93 \cdot 3)$ \\
\hline No $(\%)$ who failed & & & \\
\hline BSER $\ddagger$ & $42(12 \cdot 1)$ & $9(2 \cdot 6)$ & $23 \quad(6 \cdot 6) \S$ \\
\hline \multicolumn{4}{|l|}{ No (\%) with no } \\
\hline $\begin{array}{l}\text { otoacoustic emission: } \\
\text { Who failed BSER }\end{array}$ & $30 \quad(8 \cdot 7)$ & & \\
\hline Who passed BSER & $42(12 \cdot 1)$ & & \\
\hline \multicolumn{4}{|l|}{$\begin{array}{l}\text { No (\%) with otoacoustic } \\
\text { emission present: }\end{array}$} \\
\hline Who failed BSER & $12 \quad(3 \cdot 5)$ & & \\
\hline Who passed BSER & $262(75 \cdot 7)$ & & \\
\hline Not tested & & $12(3 \cdot 5)$ & \\
\hline Did not attend & & $2(0 \cdot 6)$ & \\
\hline Died & & $1(0 \cdot 3)$ & $2(0 \cdot 6)$ \\
\hline \multicolumn{4}{|l|}{ Risk:\| } \\
\hline Low & & & $11 \quad(3 \cdot 2)$ \\
\hline High & & & $12 \quad(3 \cdot 5)$ \\
\hline
\end{tabular}

BSER = brain stem electric response.

${ }^{*}$ Fifteen were excluded from trial.

¥The pass criteria for the BSER test was a response at $43 \mathrm{dBnHL}$ in one ear and $53 \mathrm{dBnHL}$ in the other.

\$The figure of 23 who failed BSER includes the two who subsequently died.

\|High risk is defined as those who failed the final BSER result in the worse ear at $\geqslant 73 \mathrm{dBnHL}$ if tested at a corrected age of less than one month plus those who failed at $\geqslant 63 \mathrm{dBnHL}$ if tested at a corrected age of $\geqslant 1$ month. Low risk are the remainder of the 23 who did not pass the BSER test. 


\section{Results}

The results of the otoacoustic emission and brain stem electric response tests carried out in the neonatal period and the distraction tests carried out from 8 months corrected age are presented in tables 1-5. A total of 346 babies entered the trial between August 1985 and September 1987.

For inpatients the mean time taken for each test for a sample of 92 infants was $12 \cdot 1$ minutes (range

Table 2 Follow up tests starting at 8 months of age

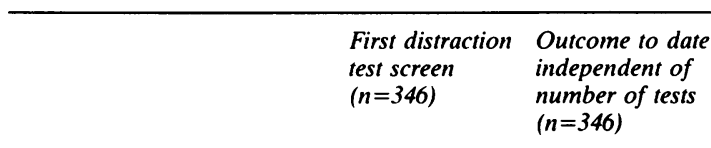

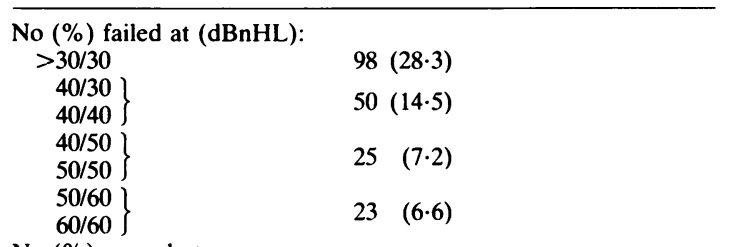

No $(\%)$ passed at $\leqslant 30 / 30(\mathrm{dBnHL})$

No $(\%)$ failed at $>30 / 30(\mathrm{dBnHL})$

$283(81 \cdot 8)$

Not able to test

Did not attend

Died

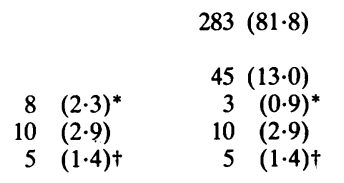

*Inconsistent $(n=1)$, uncooperative $(n=1$,

$\dagger$ Three babies died between the neonatal tests and the screen at 8 months of age. They passed the brain stem electric response at birth on first testing.
5-23) for the otoacoustic emission test and 21.0 minutes (range 11-50) for the brain stem electric response test. The mean values increased to $17 \cdot 8$ minutes $(n=19)$ and $24 \cdot 1$ minutes $(n=20)$ respectively for outpatients. The outpatients required an additional feeding time of approximately 20 minutes.

As the age of the infant increased the ability to carry out both tests successfully was reduced. Whereas between 0 and 6 weeks corrected age (post due date) the tests on all 61 babies were successful, between 7 and 12 weeks corrected age $(n=39)$ and above 12 weeks $(n=21)$ only $36(92 \cdot 3 \%)$ and $15(71.4 \%)$ respectively were successful.

Table 4 Comparison of the final outcome of BSER tests carried out in the neonatal period with the otoacoustic emission screen

\begin{tabular}{lrrrrr}
\hline & \multicolumn{3}{l}{ BSER final outcome } & Totals \\
\cline { 2 - 5 } & Pass & $\begin{array}{l}\text { Fail } \\
\text { (total) }\end{array}$ & $\begin{array}{l}\text { Fail- } \\
\text { low } \\
\text { risk }\end{array}$ & $\begin{array}{l}\text { Fail- } \\
\text { high } \\
\text { risk }\end{array}$ & \\
\hline $\begin{array}{l}\text { Otoacoustic } \\
\text { emission screen: } \\
\begin{array}{l}\text { Present } \\
\text { Absent }\end{array}\end{array}$ & 272 & 2 & 1 & $1+$ & 274 \\
\hline Totals & 51 & $21^{*}$ & 10 & $11+$ & 72 \\
\hline
\end{tabular}

BSER $=$ brain stem electric response.

*Includes one child with otoacoustic emission and BSER failures on opposite ears.

tOne child died from each of these groups.

Table 3 Comparison of the tests carried out during the neonatal period and the follow up tests starting at 8 months

\begin{tabular}{|c|c|c|c|c|c|c|}
\hline & \multicolumn{6}{|c|}{ Neonatal tests } \\
\hline & \multicolumn{2}{|c|}{ Otoacoustic emission (one test) } & \multicolumn{4}{|c|}{ BSER (final outcome) } \\
\hline & Present & Absent & Pass & Fail & & Totals \\
\hline \multicolumn{7}{|l|}{ No at final outcome who: $t$} \\
\hline Passed $\leqslant 30 / 30(\mathrm{dBnHL})$ & 234 & 49 & 270 & 13 & $(8+5)^{*}$ & 283 \\
\hline Failed $>30 / 30(\mathrm{dBnHL})$ & 28 & 17 & 38 & 7 & $(3+4)^{*}$ & 45 \\
\hline Not able to test & 2 & 1 & 2 & 1 & $(0+1)^{*}$ & 3 \\
\hline Did not attend & 8 & 2 & 10 & 0 & $(0+0)$ & 10 \\
\hline Died & 2 & 3 & 3 & 2 & $(0+2)^{*}$ & 5 \\
\hline Totals & 274 & 72 & 323 & 23 & $(11+12)^{*}$ & 346 \\
\hline
\end{tabular}

BSER = brain stem electric response.

${ }^{*}$ Figures in parentheses show division into high and low risk groups as defined in table 1.

tFinal outcome at 8 months of age (distraction test).

If the pass level for the distraction test is raised by $10 \mathrm{~dB}$ or $20 \mathrm{~dB}$ then the total number of failures (column 5) reduces from 45 to 31 or 17 . Of the 45 failing at $30 \mathrm{dBnHL} 36$ had abnormal middle ear pressures. The proportion of those with no otoacoustic emission or failing the BSER in the neonatal period who failed on follow up is significantly higher $\left(p<0.02\right.$ in each case by $\left.\chi^{2}\right)$ then the proportion of those who passed in the neonatal period and failed on follow up. 
1108 Stevens, Webb, Hutchinson, Connell, Smith, and Buffin

Table 5 Follow up of 12 infants at high risk of hearing impairment based on the result of BSER tests in neonatal period (definition in table 1)

\begin{tabular}{|c|c|c|c|c|c|c|}
\hline $\begin{array}{l}\text { Patient } \\
\text { No }\end{array}$ & $\begin{array}{l}\text { Otoacoustic } \\
\text { emission } \\
\text { Left/right }\end{array}$ & $\begin{array}{l}\text { BSER } \\
\text { screen } \\
\text { Left/right }\end{array}$ & $\begin{array}{l}\text { BSER } \\
\text { final test } \\
\text { (corrected age } \\
\text { years-months) }\end{array}$ & $\begin{array}{l}\text { Distraction } \\
\text { screen }\end{array}$ & $\begin{array}{l}\text { Distraction-final test } \\
\text { (actual age, } \\
\text { years } \cdot \text { months) }\end{array}$ & $\begin{array}{l}\text { Final } \\
\text { outcome } \\
\text { to date }\end{array}$ \\
\hline 46 & No/no & $63 / 73$ & Did not attend & $30 / 40$ & $20 / 20(1 \cdot 11)$ & Pass \\
\hline 58 & No/no & $63 / 63$ & Did not attend & $? 50 / ? 50$ & $50 / 50(1 \cdot 11)$ & $\begin{array}{l}\text { Fail. bilateral } \\
\text { conductive* }\end{array}$ \\
\hline 102 & No/no & $53 / 63$ & $63 / 63(0 \cdot 3)$ & $70 / 70$ & 30/30 (BSER) $(1 \cdot 11)$ & Pass \\
\hline 116 & No/no & $53 / 73$ & $43 / 63(0 \cdot 1)$ & $40 / 40$ & $30 / 30(1 \cdot 5)$ & Pass \\
\hline 159 & Yes/no & $53 / ? 83$ & $53 />83(0 \cdot 3)$ & Died & - & - \\
\hline 162 & Yes/yes & $\begin{array}{l}73 / 53 \\
(0 \cdot 1) \ddagger\end{array}$ & - & Died & - & - \\
\hline 167 & Yes/no & $\begin{array}{l}43 / 73 \\
(0 \cdot 2) \ddagger\end{array}$ & - & $70 / 60$ & $20 / 20(1.4)$ & Pass \\
\hline 183 & No/no & $73 / 63$ & $>83 / 43(0 \cdot 1)$ & Fail & $? / ?$ & $\begin{array}{l}\text { Inconsistent } \\
\text { results }\end{array}$ \\
\hline 224 & Atresia/no & $\begin{array}{c}\text { Atresia/43 } \\
(0 \cdot 2) \ddagger\end{array}$ & - & Atresia/60 & - & $\begin{array}{l}\mathrm{L} \text {, atresia } \\
\mathrm{R} \text {, inconsistent } \\
\text { results }\end{array}$ \\
\hline 372 & Yes/no & $43 / 73$ & $33 />83(0 \cdot 3)$ & $60 / \mathrm{NR}+$ & $50 / \mathrm{NR}+(1 \cdot 0)$ & $\begin{array}{l}\text { Unilateral } \\
\text { sensorineural* }\end{array}$ \\
\hline 383 & No/no & $\begin{array}{l}43 / 63 \\
(0 \cdot 3) \ddagger\end{array}$ & - & $80 / 80$ & $60 / 60(1 \cdot 3)$ & $\begin{array}{l}\text { Bilateral } \\
\text { mixed* }\end{array}$ \\
\hline
\end{tabular}

$\mathrm{BSER}=$ brain stem electric response.

*Not yet confirmed by bone conduction tests.

$+\mathrm{NR}=$ no response .

$¥$ Age of test (years-months) added where final test.

\section{Discussion}

Several studies have shown that the brain stem electric response threshold in neonates reduces with age when tested particularly up to 40 weeks' postconception. ${ }^{12}$ We have therefore always tried to test the babies at the oldest age possible while still in the neonatal intensive care unit. In our study some infants leave the unit well before they are old or well enough to test, particularly if they are being transferred back to their referring unit. These babies were tested as outpatients where possible. One solution to this problem is to use a higher pass criteria if the baby is tested at a younger age. We rejected this solution as there is considerable variation in threshold at any age and the use of a higher pass level may reduce the number of hearing impaired babies detected.

Both tests have proved practical. The number of babies who had to be rejected from the study was only 15 compared with the 346 who were successfully tested. In all cases but one this was due to excessive activity at the time the test was attempted. We have previously reported the time it took to carry out each test ${ }^{7}$; this was based on a small sample early in the study. The results given in this paper are of a more detailed investigation carried out at a later date. The mean time to carry out an otoacoustic emission compares very favourably with the distraction test used to screen for hearing impairment at 8 months. It is also safe, non-invasive and, unlike the distraction test, only requires one tester. The brain stem electric response test requires longer, largely as a result of the time required to attach the electrodes. The results also show that, for this test, babies tested as outpatients at a mean corrected age of 7 weeks required only a slightly longer test time, although the total time was considerably longer due to the delays while the baby was being fed before the test. As the age increases, however, the results show that the proportion of babies who will not sleep for the test rises and a practical age limit for this method appears to be about 3 months. Although a higher proportion may fail either test while in the unit than at an older age, the additional costs of the latter in time and appointment procedure for the hospital and family and the problems of non-attendance mean that these screening tests (from a cost point of view) are best carried out before the infant leaves the unit.

One of the main questions of any screening procedure is-does it pass a sufficiently high proportion of the populations being tested? The results in table 1 show that $79 \%$ of the infants 
produce an otoacoustic emission in both ears on first testing. There was little change in the figures for sequential groups of 100 babies entering the study who produced an emission in both ears $(81 \%, 78 \%$, and $83 \%$ ). Possible reasons why $21 \%$ do not produce an emission are discussed in our earlier report. ${ }^{7}$ The pass rate of the brain stem electric response test is higher but, in a more detailed study (to be published), it was found to be very dependent on the stimulus level used for the pass criteria. For example at a pass level of $43 \mathrm{dBnHL}$ in each ear the pass rate for the brain stem electric response test was found to be lower than the $79 \%$ for the otoacoustic emission test.

We were able to retest (table 1) 27 of the 42 babies who did not pass the first screen. The fact that two thirds of these passed on second testing indicates that on a two test brain stem electric response screen at the stimulus levels used in our study the final pass figure would be $96 \%$. The final outcome of the brain stem electric response testing in the neonatal period left 23 infants who had not been passed. This group was further divided by the brain stem electric response threshold into a group at 'high risk' and 'low risk' of hearing impairment. Some babies who could not be recalled for further brain stem electric response tests had their last test at below a corrected age of 1 month. The criteria for the high risk group takes this into account by changing the criteria at 1 month of corrected age (see table 1). This is based on the reports in the literature that the brain stem electric response threshold reduces with age. ${ }^{12}$

There is a wide range of published values for failure rates for the brain stem electric response tests carried out on high risk infants at birth. In their review Murray et al give an average failure rate of $16.5 \%$ with a range of 9 to $39 \% .^{3}$ We have shown that by retesting it is possible to reduce this figure to $6.6 \%$ and if we had retested all the infants to a predicted $4 \%$. This figure is in close agreement with Nield $e t$ al who report an initial failure rate by brain stem electric response of $18.8 \%$ and a failure rate of $3 \cdot 2 \%$ on retesting for 605 graduates of a neonatal intensive care unit. ${ }^{11}$ As noted in the method section the brain stem electric response pass criteria we used-of $43 \mathrm{dBnHL}$ in one ear and $53 \mathrm{dBnHL}$ in the other-we consider to be reasonable to detect clinically important hearing impairment. It is clear from retrospective studies such as that by Newton, ${ }^{1}$ however, that the long term incidence of sensorineural hearing impairment is much lower than these brain stem electric response failure rates would indicate. She found that the incidence of bilateral sensorineural hearing loss to be $0.08 \%$ overall. This increased to $0 \cdot 5 \%$ of live births ( $1 \cdot 1 \%$ of survivors) for babies of birth weight less than $1500 \mathrm{~g}$. Our mean birth weight was $2220 \mathrm{~g}$. A rate of between 0.08 and $1 \cdot 1 \%$ would therefore be expected for bilateral sensorineural hearing loss; this is much lower than the brain stem electric response fail rate. Careful examination must therefore be made of those babies failing the brain stem electric response at birth to decide which are in this category and will need treatment.

The results of the first screen by the distraction test at 8 months show the highest failure rate of all three screening tests. Like the brain stem electric response test at birth the failure rate is very dependent on the stimulus level used. The number reduces by one half for a $10 \mathrm{~dB}$ rise in the pass criteria from 30 to $40 \mathrm{dBnHL}$ (table 2).

The final outcome of the follow up tests to date leaves 45 infants who have not passed at $30 \mathrm{dBnHL}$, three who could not be tested, and 10 who could not be recalled. All of the latter passed the brain stem electric response test at birth. Although this figure is reducing as further tests are carried out, the 45 infants who did not pass represent twice the proportion of those not passed at birth. One possible reason for this could be that the pass criteria at $30 / 30 \mathrm{dBnHL}$ will fail a higher proportion than that used for the brain stem electric response test (43/53 dBnHL). Raising the pass level by $10 \mathrm{~dB}$ reduces the number who failed from 45 to 31 and raising it by $20 \mathrm{~dB}$ reduces it to 17 (table 3 ). Whichever criteria is used, however, there is little agreement between the results at birth and those at 8 months, although the results show significance $\left(\mathrm{p}<0.02\right.$ by $\chi^{2}$, table 3$)$. This is in contrast with the much closer association between the outcome of the otoacoustic emission screen and the brain stem electric response test at birth (table 4$)(p<0.0001$ by $\chi^{2}$ ). Twenty of the 21 infants who failed the brain stem electric response on final outcome and survived would have been detected by the otoacoustic emission screen. Note though that in one infant opposite results were obtained on the two ears for the brain stem electric response and otoacoustic emission tests. These results in table 4 produce sensitivity and specificity values of the otoacoustic emission test for brain stem electric response final outcome of $95 \%$ and $85 \%$ respectively.

A large proportion of the 45 infants not passed by the follow up tests to date had negative middle ear pressures (table 3). Only nine infants of this group were reported as having normal middle ear pressures. All of these nine passed the brain stem electric response on final outcome at birth.

The lack of agreement between the results in the neonatal period and those in the follow up period starting at 8 months corrected age raises the question 


\section{Stevens, Webb, Hutchinson, Connell, Smith, and Buffin}

of whether a prospective study can prove that the tests at birth are correct. Both the figures of 23 out of 346 at birth and 45 out of 346 at 8 months are high compared with the expected number for a neonatal intensive care unit population, as noted above, and must contain many false positives. The lack of agreement may simply be due to different causes of false positives in the neonatal period and in the follow up period. There are many reports in the literature of higher incidences than that reported here of hearing impairment in neonatal intensive care unit populations studied by brain stem electric testing. Murray et al, in their review of studies on brain stem electric response screening in the newborn, report a variation of between $1 \%$ and $22 \%$ in the number of 'hearing impaired' from follow up work. ${ }^{3}$ The confirmation rate-that is, the proportion of brain stem electric response failures later confirmed as 'hearing impaired'-varied from $4 \cdot 8 \%$ to $100 \%$.

In the study by Galambos et al on babies from an intensive care nursery (which represents about half of the infants reviewed by Murray et al where the follow up work had been carried out) overall $16 \cdot 1 \%$ failed the $30 \mathrm{dBnHL}$ brain stem electric response screen at birth. ${ }^{13}$ From the $54 \%$ of those that attended the retesting it was estimated that for the whole sample of 1613 infants unilateral and bilateral hearing impairments would be found in $2.8 \%$ and $6 \%$ respectively and hearing aids fitted to $4 \%$. A figure of above 1:100, however, seems unlikely from a consideration of total population incidence and published retrospective data. McCormick et al, who studied the use of the auditory response cradle in a neonatal intensive care unit similar to ours,${ }^{14}$ found three bilateral sensorineural hearing impaired infants among the 396 tested, which is much closer to this figure than some of the high figures reported in the literature. The wide range of values reported by Murray et al for the percentage of hearing impaired $(1-22 \%)$ and the wide range of confirmation rates of $4 \cdot 8-100 \%$ indicate that the brain stem electric response test as a prognostic indicator of permanent hearing impairment is far from established.

Most studies on the use of brain stem electric response at birth involving large numbers of infants, reviewed by Murray et al, ${ }^{3}$ have only followed up brain stem electric response failures. Nield $e t$ al, however, report 11 graduates of a neonatal intensive care unit who passed the brain stem electric response at birth (response at $30 \mathrm{dBnHL}$ ) and were subsequently found to be hearing impaired, and seven of these were profound. ${ }^{11}$ There was, however, evidence of hearing in some of these infants later on in the first years of life. Galambos et al considered that false negatives would be rare. ${ }^{13}$ This may be true in adults but the results of Nield $e t$ al suggest that when considering long term hearing impairment the use of results of the brain stem electric response carried out at birth may be limited. ${ }^{11}$ Duara et al report on a sample of 278 infants tested by brain stem electric response at birth of whom 159 were from the intensive care nursery. They again show that false positives can occur. ${ }^{15}$ Twenty seven of the 35 who failed the brain stem electric response screen at birth (no response at $35 \mathrm{dBnHL}$ in either ear, pass if response at $35 \mathrm{dBnHL}$ in first ear tested) had an initial audiological follow up between the ages of 4 and 17 months. Otological examination showed no abnormality suggestive of conductive hearing loss in any of these 27 infants. Ten of the 27 infants had abnormal hearing. In subsequent follow up six gradually improved and of the four that persisted three were fitted with hearing aids. Of the four who had no brain stem electric response at $80 \mathrm{dBnHL}$ at birth, the follow up results were one normal, one gradual improvement, and two with persistent hearing impairment.

In our study none of the 12 infants who were classified as being at high risk of hearing impairment from the neonatal brain stem electric response tests (table 5) passed their 8 month screen, although two gave responses at or below $40 / 40 \mathrm{dBnHL}$. Five went on to pass at $30 / 30 \mathrm{dBnHL}$ by the age of 2 years. Of the remaining five, one is thought to have a unilateral sensorineural hearing loss, one a bilateral mixed loss, one a bilateral conductive loss, and two have given inconsistent results and no conclusion has been reached to date. Baby number 65 illustrates the need for continuous follow up. No brain stem electric responses were recorded on three occasions in the neonatal period up to $83 \mathrm{dBnHL}$. At 10 months there were responses to low frequencies only at $70 \mathrm{dBnHL}$. The hearing threshold then appeared to improve and was normal by the age of 14 months. Baby 102 is a less extreme example of the same results. This sort of result is similar to some of those reported by Duara et al as noted above. ${ }^{15}$ If the combination of otoacoustic emission and brain stem electric response or brain stem electric response on its own is to be used to screen for hearing impairment then it is clear that continuous monitoring of failures is required and no conclusions on the long term outlook must be drawn.

Although this report is only on the first 346 babies in our study, we are able to draw several useful conclusions on the application of the click evoked otoacoustic emissions and brain stem electric response audiometry to detect the hearing impaired at birth. Both tests pass a sufficient proportion to be considered as a screening procedure. Consideration of the shorter time required for the otoacoustic 
emission test, the detection of nearly all (20/21 who survived) of those who failed the brain stem electric response on the final outcome of the tests in the neonatal period, and it being less invasive that the brain stem electric response test indicate that it would make the better screening test. A brain stem electric response test carried out at the same time on babies not producing an otoacoustic emission would make a good complementary test. If this procedure were implemented our results indicate that, for the population tested in our study, $79 \%$ would pass the otoacoustic emission test. A further $12 \%$ would pass the brain stem electric response test carried out on those not producing an emission leaving $9 \%$ to be followed up. As the click evoked otoacoustic emission cannot determine the degree of hearing impairment then the brain stem electric response test would be used for this. The high pass rates and the low cost of carrying out the tests while the babies are still in the unit indicate that this is the best time at which to carry out the screening test.

The final outcome of the follow up tests to date, however, show poor correlation with the final outcome of the neonatal tests. For example only seven of the 21 surviving infants who failed brain stem electric response at birth failed on follow up (outcome to date) at $30 \mathrm{dBnHL}$. This was out of a total of 45. Raising the pass/fail level of the distraction test by $10 \mathrm{~dB}$ to $40 \mathrm{dBnHL}$ did not alter this lack of agreement greatly $(6 / 21$, total 31$)$. The difficulties of the distraction test are illustrated by the high proportion who fail on first testing, although this was found to be very dependent on the pass criteria. It is not yet possible to say how many hearing impaired babies we have missed until the 45 failures on follow up have been further tested. There are many possible explanations for this disagreement between tests carried out in the neonatal period and those on follow up-for example, undetectable responses, temporary middle ear disease, delayed neurological development. It must be concluded, however, that it is not possible to use the distraction test results to determine if the tests at birth were correct at that time.

In conclusion we have found that the otoacoustic emission can detect most of those infants who will not pass the brain stem electric response in the neonatal period, but it is clear that the prognostic value of brain stem electric response is not yet established. Any prospective study investigating the ability of these tests to detect hearing impairment at birth must follow up each failure at very frequent intervals if a fuller understanding of the reliability of these tests in the first year of life is to be established. Although the early fitting of hearing aids is desirable, the results presented here and those in the literature express the need for caution in using the results measured in the neonatal period. Continuous monitoring of the hearing threshold of any infant failed at birth is obviously essential.

The authors would like to acknowledge the financial support of the Trent Regional Health Authority, the Hawley Trust, and Trustees of the United Sheffield Hospitals.

\section{References}

1 Newton VE. Aetiology of bilateral sensori-neural hearing loss in young children. J Laryngol Otol 1985;suppl 10:40-1.

2 McCormick B. Hearing screening by health visitors-a critical appraisal of the distraction test. Health Visitor 1983;56:449-51.

${ }^{3}$ Murray A, Javel E, Watson CS. Prognostic validity of auditory brainstem evoked response screening in newborn infants. Am J Otolaryngol 1985;6:120-31.

${ }^{4}$ Kemp DT. Stimulated acoustic emissions from within the hearing system. J Acoust Soc Am 1978;64:1386-91.

5 Johnsen NJ, Bagi P, Elberling C. Evoked acoustic emission from the human ear. III. Findings in neonates. Scand Audiol 1983;12:17-24.

6 Elberling C, Parbo J, Johnsen NJ, Bagi P. Evoked acoustic emission: clinical application. Acta Otolaryngol (Stockh) 1985; suppl 421:77-85.

${ }^{7}$ Stevens JC, Webb HD, Smith MF, Buffin JT, Ruddy H. Comparison of oto-acoustic emissions and brain stem electric response audiometry in the normal newborn and babies admitted to a special care baby unit. Clin Phys Physiol Meas 1987;8:95-104.

8 Kemp DT, Bray P, Alexander L, Brown AM. Acoustic emission cochleography-practical aspects. Scand Audiol [Suppl] 1986;25: 71-95.

9 Stevens JC, Ip B. Click evoked oto-acoustic emissions in normal and hearing impaired adults. Br J Audiol 1988;22:45-9.

10 Rutten WLC. Evoked acoustic emissions from with abnormal human ears: comparison with audiometric and electrocochleographic findings. Hear Res 1980;2:263-71.

11 Nield TA, Schrier S, Ramos AD, Platzker AC, Warburton D. Unexpected hearing loss in high-risk infants. Pediatrics 1986;78: 417-22.

12 Guerit JM. Applications of surface recorded potentials for the early diagnosis of hearing loss in neonates and premature infants. Acta Otolaryngol [Suppl] (Stockh) 1985;421:68-76.

${ }^{13}$ Galambos R, Hicks GE, Wilson MJ. The auditor reliably predicts hearing loss in graduates of a tertiary intensive care nursery. Ear and Hearing 1984;5:254-60.

${ }^{14}$ McCormick B, Curnock DA, Spavins F. Auditory screening of special-care neonates using the auditory response cradle. Arch Dis Child 1984;59:1168-72.

15 Duara S, Suter CM, Bessard BS, Gutberlet RL. Neonatal screening with auditory brainstem responses: results of follow up audiometry and risk factor evaluation. J Pediatr 1986;108: 276-81.

Correspondence to Dr JC Stevens, Department of Medical Physics and Clinical Engineering, Royal Hallamshire Hospital, Sheffield S10 2JF.

Accepted 11 April 1989 